\title{
Fuzzy Cognitive Map Applied in Low-Cost Mobile Robot Exploring Unknown Environment
}

\author{
Márcio Mendonça*. Guilherme B. Sartori*. \\ Lucas B. de Souza*. Giovanni B. M. Ribeiro*. Rodrigo H. C. Palácios*
*Federal University of Technology - Paraná, Cornélio Procópio, Brazil; (e-mails: mendonca@utfpr.edu.br; guibender.sartori@gmail.com; lucsou@alunos.utfpr.edu.br; giovanniribeiro@alunos.utfpr.edu.br; rodrigopalacios@utfpr.edu.br)

\begin{abstract}
Autonomous Navigation Systems still have some barriers to break. The decision-making process of autonomous robots tend to have high computational costs, and still feel distant to being used in everyday tasks. This paper presents an evolution of a previous work, where the major aspect discerning both papers is the objective finding routine, as the robot does not know its destination anymore. We propose using Fuzzy Cognitive Maps (FCM) to control the decision-making process of a low-cost autonomous mobile robot, that can be used for modeling and testing small scale prototypes. The system is embedded using an ATMega2560 microcontroller and the motors' actuation will be inferred directly from sensors reading. This approach presents a smoother detour and optimized trajectory, when compared to a multivalued logic controller. With low computational costs, and minimal adjustments, FCMs have proven to be useful as an embedded decision-making mechanism. Finally, future works will conclude this research.
\end{abstract}

Resumo: Sistemas de Navegação Autônoma ainda possuem algumas barreiras a serem transpassadas. processo de tomada de decisão de robôs autônomos tende a ter alto custo computacional, e ainda parece estar distante de ser usado em tarefas cotidianas. Este artigo apresenta uma evolução de um trabalho anterior. O principal aspecto que difere os dois trabalhos é a rotina de busca objetiva, pois o robô não conhece mais seu destino. A utilização de Mapas Cognitivos Fuzzy (FCM) é proposta para controlar o processo de tomada de decisão de um robô móvel autônomo de baixo custo, que pode ser usado para modelar e testar protótipos de pequena escala. O sistema é embarcado usando um microcontrolador ATMega2560 e a atuação dos motores será inferida diretamente da leitura dos sensores. Essa abordagem apresenta um desvio mais suave e uma trajetória otimizada, quando comparada a um controlador de lógica multivalorada. Com baixos custos computacionais e ajustes mínimos, os FCMs provaram ser úteis como um mecanismo incorporado de tomada de decisão. Finalmente, trabalhos futuros concluirão esta pesquisa.

Keywords: Fuzzy Cognitive Maps; Autonomous Mobile Robot; Embedded Systems.

Palavras-chaves: Mapas Cognitivos Fuzzy; Robô Móvel Autônomo; Sistemas Embarcados.

\section{INTRODUCTION}

Robots were developed to help human beings, to improve working conditions and to conduct potentially hazardous activities. Considering this, the development of autonomous mobile robots can aim to reach regions that can be dangerous to the human health (Siegwart and Nourbakhsh, 2004). The application of these robots is constantly growing: such is the example of the Mars Rover, an autonomous mobile robot that explores the surface of Mars.

Recently, we can cite the InSight mission (Fig. 1), which arrived in Mars in November of 2018. The rover is projected to stay in a single location monitoring the surface of the planet. It has sensors to detect seismic activities, and cameras to look out the planet surface. Due to the distance between the planets (over 480 million $\mathrm{Km}$ ), the communication delay (approx. 8 min) limits the control of the vehicle. Thus, the rover must have autonomous functionalities (NASA, 2018).

There is a developing interest for the improvement of selfruling robots and vehicles, as different levels of autonomy are required for different applications. Some examples of mobile robots and their usage can be seen in welding, condition investigation, submerged and other situations that might present hazard to human health (Mendonça et al., 2013). Small and low-cost robots can be used to survey these areas from a closer perspective and can also be able to locate victims of natural disasters. The recent growth of swarm robotics can also be mentioned, as these robots can be used together for exploration of larger areas (Yanguas-Rojas and Mojica-Nava, 2017).

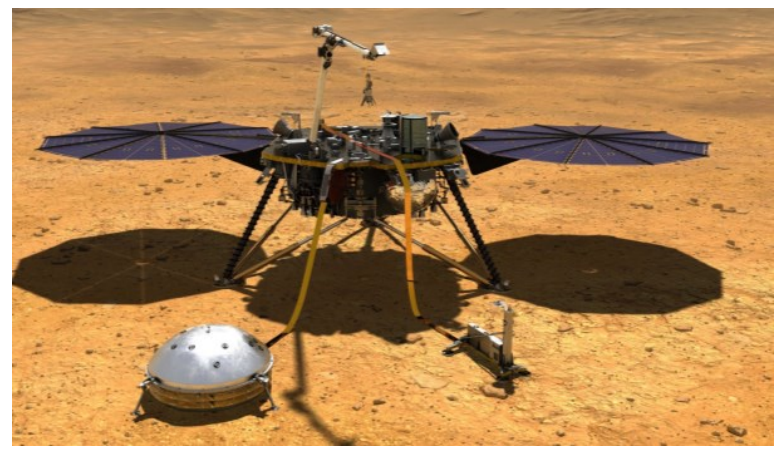

Fig. 1 InSight Rover. 
This paper proposes embedding FCMs in the ATMega2560 microcontroller, a low-cost processing unit that can be used in autonomous robots (de Souza et al., 2017). Also, with further experimentation and focused implementation, different modes of operation can be developed for specific needs. This control method can be further improved to be used in groups of cooperative autonomous mobile robots (Arruda et al., 2018). Which, can be refined to perform any desired task, such as: aiding people in a daily basis, surveillance, exploration, search and rescue missions, etc.

Regarding cooperation of different systems, we can cite the industry 4.0 concept, in which industrial machines or active systems are characterized by the use of network-based intelligent systems, in order to provide greater flexibility, efficiency and integration with the entire production chain (Robla-Gomez et al., 2017).

From the broad knowledge of the environment with a large amount of information obtained (Big Data), it is possible, through intelligent systems, to make decisions with greater precision in a collaborative way. Groups of robots can promote the sharing of data and information, besides performing specific activities (Arruda et al., 2018). Therefore, these entities can be aligned to some mechanical functions in logistic collaboration, in variable monitoring issues and even in the identification and search of victims in large-scale accidents.

This work is divided as follows: Section 2 presents the necessary fundamentals for understanding the research, such as Mobile Autonomous Robots and Kinematic Model. Also, a background on Fuzzy Logic and FCMs. Section 3 presents real results of the prototype and comparison with multivalued logic. And, finally, Section 4 concludes and suggests future investigations of this research.

\section{ROBOT DEVELOPMENT}

Robotics is a multidisciplinary field, having multiple backgrounds depending on the required application, for this project, there are topics related to mechanical, electrical and computer engineering. This section describes the background and fundamentals used while developing the prototype presented by this article.

\subsection{Mobile Autonomous Robots}

Robots are defined by Bekey (2005) as machines that, from a perception of the environment, handle the information acquired to act according to it. For that to happen, a robot needs sensors, processing ability, and actuators. This way, a robot can perform reactive behaviors or independent tasks and exert forces upon its surroundings. These principles are important as a robot must be able of reacting to obstacles and emerging events quickly (Steels, 1995). Multiple cooperating robots can perform tasks more reliably and faster than a single robot, as the communication between a group of robots can multiply their effectiveness (Mendonça et al., 2017). Multi-Agent Systems (MAS) are usually required to solve problems in dynamic and unpredictable environments.

A major aspect regarding robotic agents is autonomy, which is the capacity of self-government. Thus, a robot can act and make decisions without external influence, from users or programmers. An autonomous agent must make the decisions that will lead to its objective, while considering any goals that must be completed along the way (Steels, 1995; Grassi Jr, 2006). The term "Collective Intelligence", in MAS, refers to elaborated collective behaviors that can arise from a combination of many agents. With relatively simple behavior and action, each operating autonomously (Mendonça et al., 2017).

Exploration tasks involving a multi-robot system (MRS) require a set of skills to be individually performed by each mobile robot, in order to achieve a decentralized and cooperative behavior (Mendonça et al., 2013; Robla-Gomez et al., 2017). These individual capabilities can be broken down into different segments. As proposed by Brooks (1986), the subsumption architecture describes that an agent's design can be decomposed into behaviors, such as obstacle avoidance, exploration, or following lines. Each module can access sensorial inputs independently, as a manner of extracting the information it needs and send its own signal to the actuators.

The embedded architecture used by this project decomposes two main behaviors and can be seen in Fig. 2. The main objective is finding a colored tile on the ground. A secondary objective is obstacle avoidance, thus representing a goal set along the way, as the robot should not hit anything in its path.

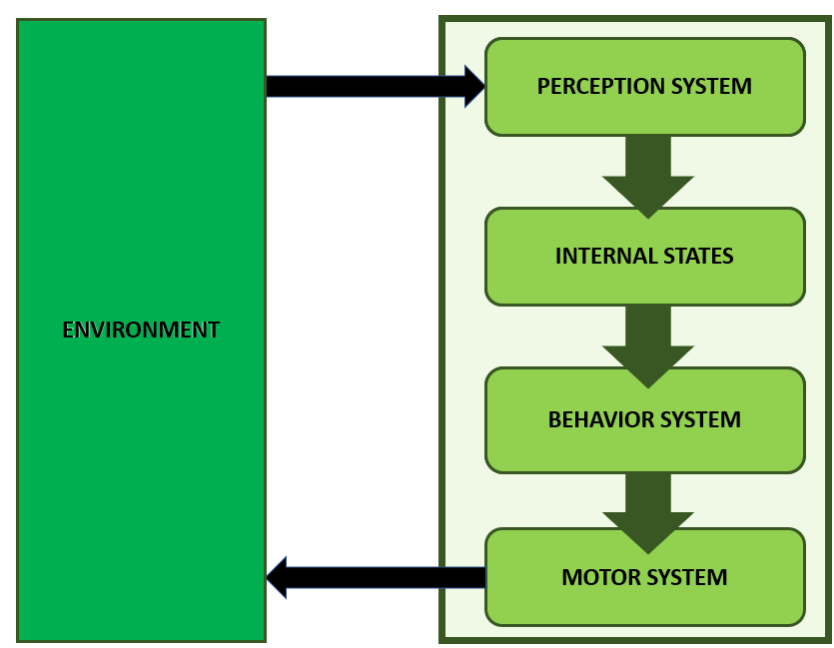

Fig. 2 Embedded system architecture.

Those behaviors where implemented by creating a finite-state machine with two internal states. The first state looks for the objective while trying to avoid all obstacles found along the way. The second state is achieved when the colored tile is found, which leads to the robot stopping. In addition, this state can be implemented with multiple objectives that can be set according to different needs. As an example: if different colored tiles are found, each color can be set as an objective or a secondary goal that makes the robot perform a desired action according to that tile. This can be used in MRS, as the robots can use a different colored terrain to mark a path or a point of mutual interest.

\subsection{Prototype Structure and Kinematic Model}

One of the challenges of mobile robotics is to measure the distance that each wheel travels and, being a robot with 
differential wheels a non-holonomic vehicle, it is not trivial to estimate its position. Thus, there is no direct way to measure the position of a mobile robot instantly, and it is necessary to integrate the movement of the robot over time (Siegwart and Nourbakhsh, 2004).

A system is defined as non-holonomic when the trajectory closed in its configuration in space may not return to its original state. That is, a car or robot with non-differential wheels are non-holonomic vehicles, because to make a mobile robot return to its initial position requires not only that the two wheels turn back the same number of times, but it is also necessary to calculate its relative velocity. In order to specify the position of the robot in the plane, it is necessary to establish a relation between the global reference map of the plane and the local reference map of the robot (Siciliano and Khatib, 2007).

As seen in Fig. 3, the $X I$ and $Y I$ axes define an arbitrary base of inertia in the plane as a global reference map of origin $O$ : $\{X I, Y I\}$. To specify the position of the robot, a point $P$ is chosen in the robot chassis, where the base $\{X R, Y R\}$ defines two axes relative to $P$ as the local reference position. The position of $P$ in the global reference is specified by the coordinates $x$ and $y$, and the angular difference between the global and local maps is given by $\theta$. With this, the robot pose is described as a vector of these three elements $(x, y, \theta)$ (Siegwart and Nourbakhsh, 2004).

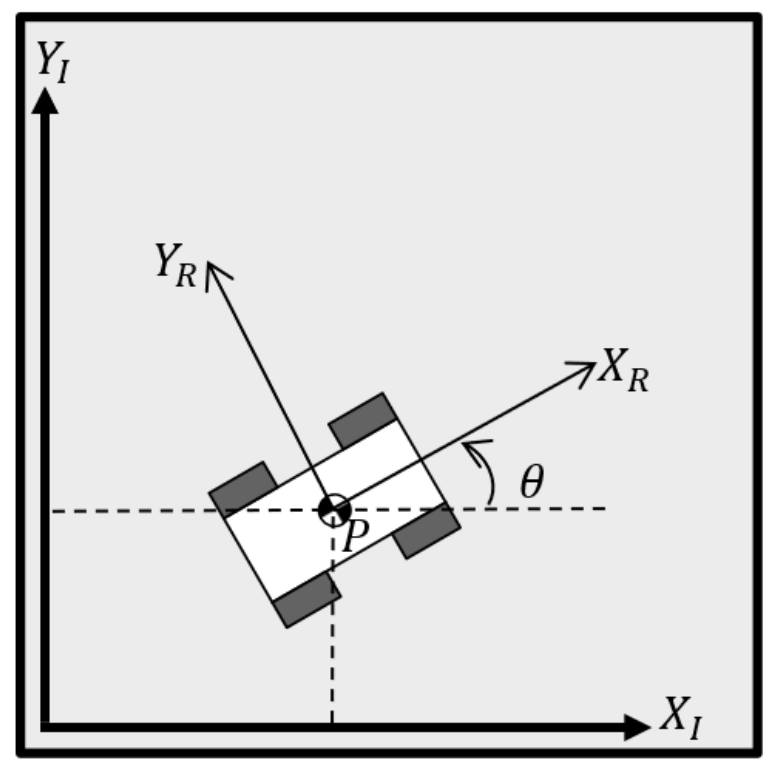

Fig. 3 Prototype kinematics.

As mentioned previously, a mobile robot needs the ability to sense, think and act. For that, robots rely on sensors, processing ability and actuators. There are several different types of sensors, each is designed for a range of applications (Correl, 2016). For this project we used two different models of distance sensors, which are used together, in order to complement each other, aiming to minimize errors and flaws while improving accuracy for obstacle detection. The color sensor is used to find the main objective. Three different sensor types were used: Three Ultrasonic Ranging Modules (HCSR04); Two Time-of-Flight Distance Sensors (VL53L0X); One Color Light-to-Frequency Converter (TCS3200). The processor is an ATMega2560 microcontroller. Finally, an Hbridge circuit (Monster Motor Shield) was added to control four DC motors

We used a microcontroller embedded with an FCM to make the decisions. The ATMega2560 was selected due to its availability and low-cost. The structure of the micro controller is enough for embedding the robot's routines of obstacle avoidance and objective assessment, supplying the computational needs of the prototype. Beyond processing abilities, it can manage and control the several inputs and outputs required from all sensors and actuators used in the project., This microcontroller also offers practicality, as user created libraries can aid in reducing code length, minimizing errors and simplifying program maintenance.

The prototype presented by this paper has a completely new structure, with significant improvements regarding the machine previously presented by Mendonça et al. (2016) which can be seen in Fig. 4. Due to the necessity to accommodate more peripherals, an additional set of motors and a bigger battery where added to improve performance. The new version of the prototype respects the kinematic model, but has a bigger structure overall.

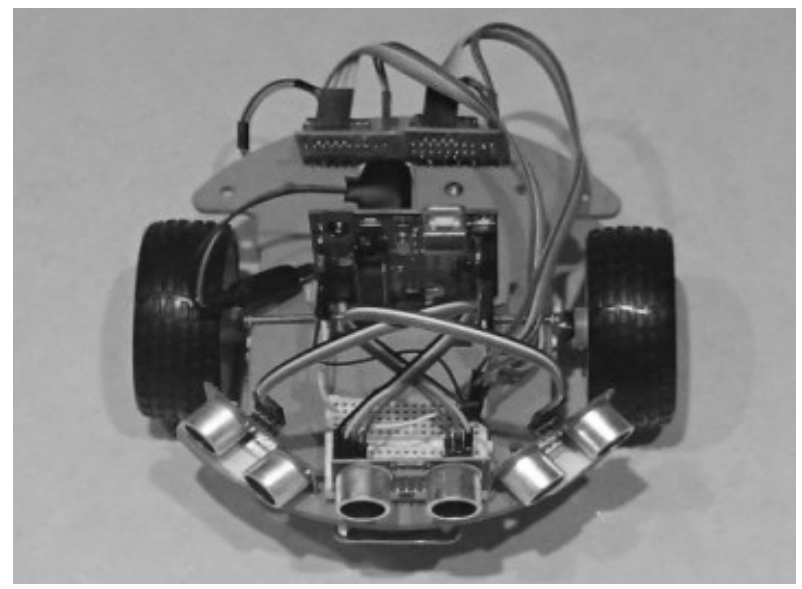

Fig. 4 Previous prototype upper vision.

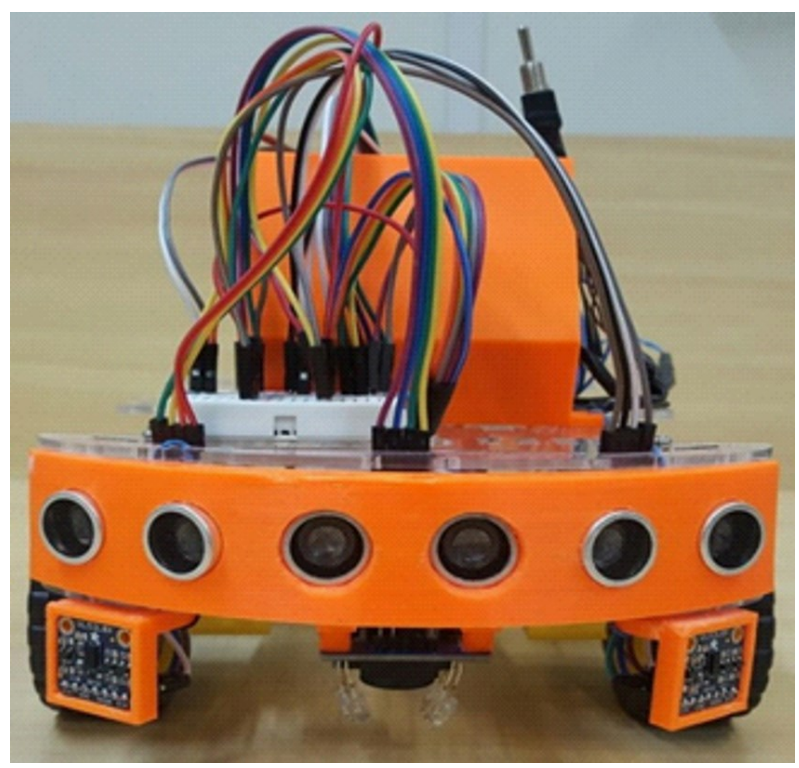

Fig. 5 New prototype frontal vision. 
The sensors and battery support where $3 \mathrm{D}$ printed and mounted over an acrylic chassis. The design was created to fit all the components used, including the batteries and can be seen in Figs. 5 and 6 . There are many peripherals and everything is attached to the main structure, mounted in the breadboard. If there are any unexpected failures, component replacement is at hand. For a future improvement, we intend to solder everything into a built-in circuit with, if possible, interchangeable modules to make maintenance easier. This modification still needs improvement and better assessment to be developed.

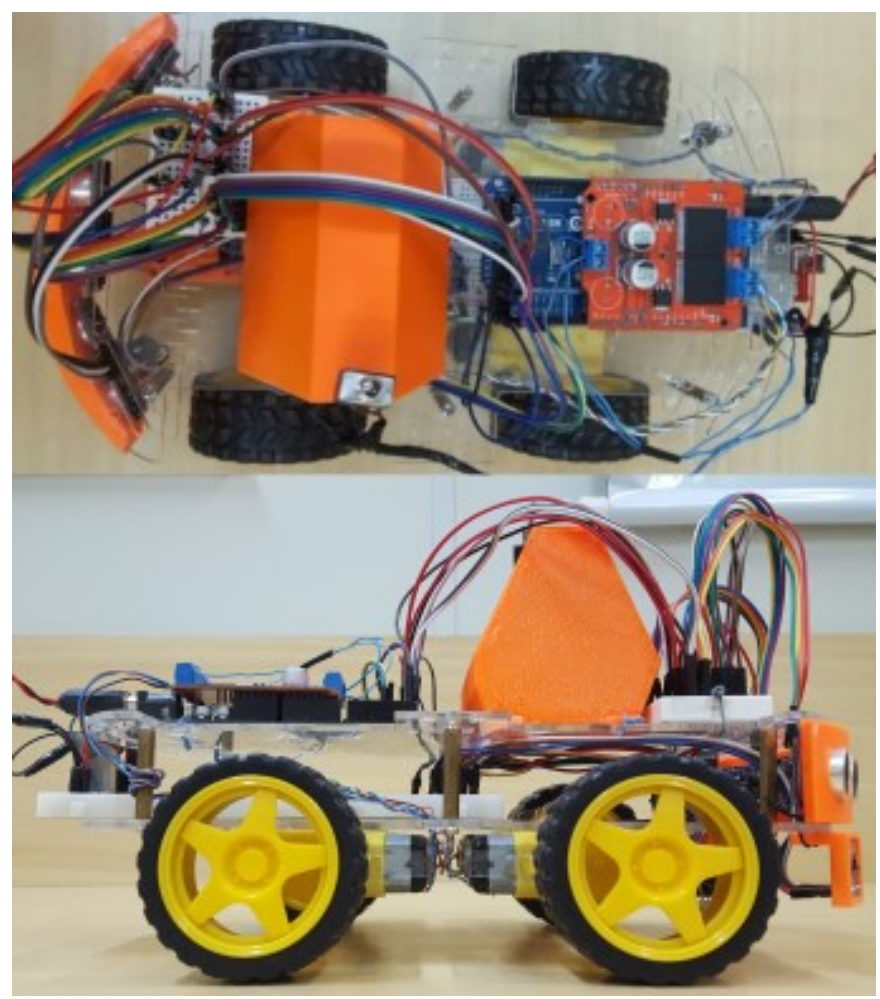

Fig. 6 New prototype upper and side visions.

For this project, we aimed for a low cost autonomous mobile robot, which must be able to move around without being restrained by the environment it will explore. The prototype is a car-like robot, it has four DC motors, each has a fixed wheel connected to a reduction box (46:1). These actuators are controlled by an integrated H-bridge circuit (Monster Motor Shield), driven by the FCM embedded in the microcontroller. This approach attempts to make a fast reaction from the robot to any fixed or dynamic obstacle, while still being a smooth change in route.

\subsection{Fuzzy Cognitive Maps}

Successful controllers need to make the right decisions in uncertain situations, fuzzy logic controllers can provide approximate reasonings, using commonsense rules and natural language statements, necessary for autonomous navigation. These control structures can include deliberative and reactive rule sets, being able to continuously interpolate between them (Ruspini, 2002; Tunstel and Jamshidi, 2002).This interpolation between behavioral sets lead to smooth transitions on objective seeking and avoiding obstacles routines.

The decision-making process embedded in the prototype is driven by FCMs, which are fuzzy graphic structures used to represent causal thinking, which allows degrees of causality between different concepts (Kosko, 1986). According to Papageorgiou (2014), these concepts are important elements of the system, having directed edges that represent the relation between them. These edges are labeled with fuzzy values using intervals of $(0,1)$ or $(-1,1)$, representing the impact concepts infer on each other. When the FCM is ready, it can receive data from the input concepts, to calculate the decisions using (1) and (2) and infer the decisions as output concept values.

$$
\begin{aligned}
& A_{i}=f\left(\sum_{\substack{j=1 \\
j \neq i}}^{n}\left(A_{j} \times W_{j i}\right)+A_{i}^{\text {old }}\right) \\
& f(x)=\frac{1}{1+\exp (-\lambda x)}
\end{aligned}
$$

The FCM model used by this paper has evolved from Mendonça et al. (2016), where the motors are driven by the sensor readings. The FCM design can be seen in (Fig. 7), they are similar but the relational weights presented by this paper are different from those presented by its predecessor.

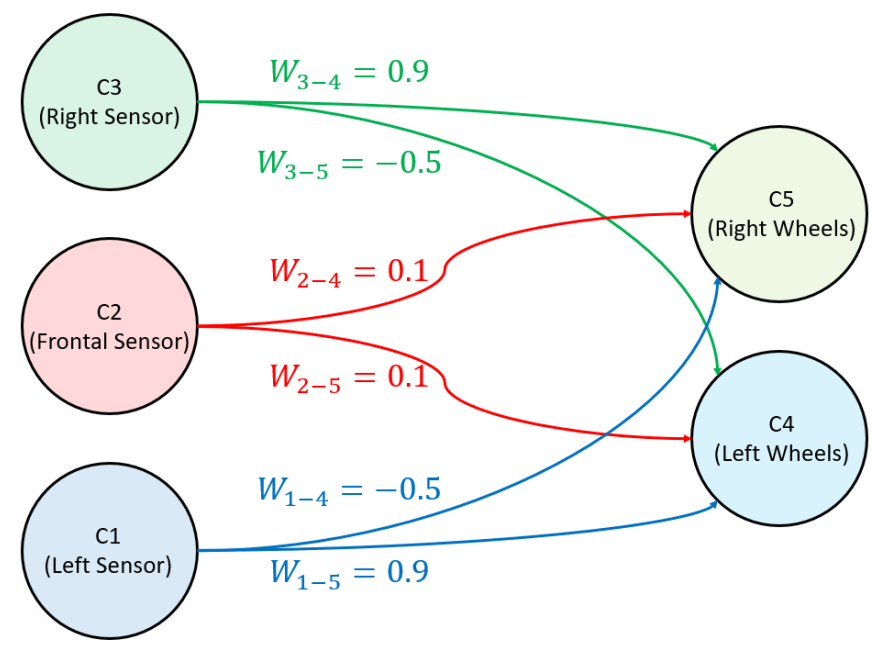

Fig. 7 Obstacle avoidance FCM.

A major difference is that the state machine does not know the location of the target. This way, we don't need to use an HDFCM that will lead the final destination, as the objective searching routine is constantly looking for it.

The obstacle avoidance routine proposed by this prototype will work with the sensor's readings regarding the robot's surroundings, which will directly actuate the motors. Then, the acquired data will go through the inference equation. This is where the decision-making process will infer to where the robot must go. The direction of the movement will be according to the obstacles detected at that loop, so the motors must move the robot away from anything that it might collide with and go through another loop. In other words, if the robot detects an obstacle on its left-hand side it must move to the right, or the other way around. If there are no obstacles detected by the sensors, the robot will move forward. 


\section{RESULTS AND DISCUSSION}

The biggest challenge of working with autonomous agents is autonomy itself (Bekey, 2005), in this case, being autonomous means to perform and reach the objective through different scenarios. The proposed robot was tested in random environments, with different obstacle disposition. Each route was tested twice, in the first run we used multivalued logic (ifthen rules with crisp values) with predetermined reactions to sensor stimuli, this approach was used as control. The second test in the same scenario used the embedded FCM.

The first scenario tested was used to validate both models, and consisted in an open space with randomly disposed obstacles. This scenario was used to test the robots' decision-making capacity in an open area, with many fixed and a few dynamic obstacles. In our initial real results, the robot reached the destination without human intervention and trajectory programming, through random environments. Therefore, proving it to be completely autonomous. The robot made several runs through different scenarios and both logics performed similarly.

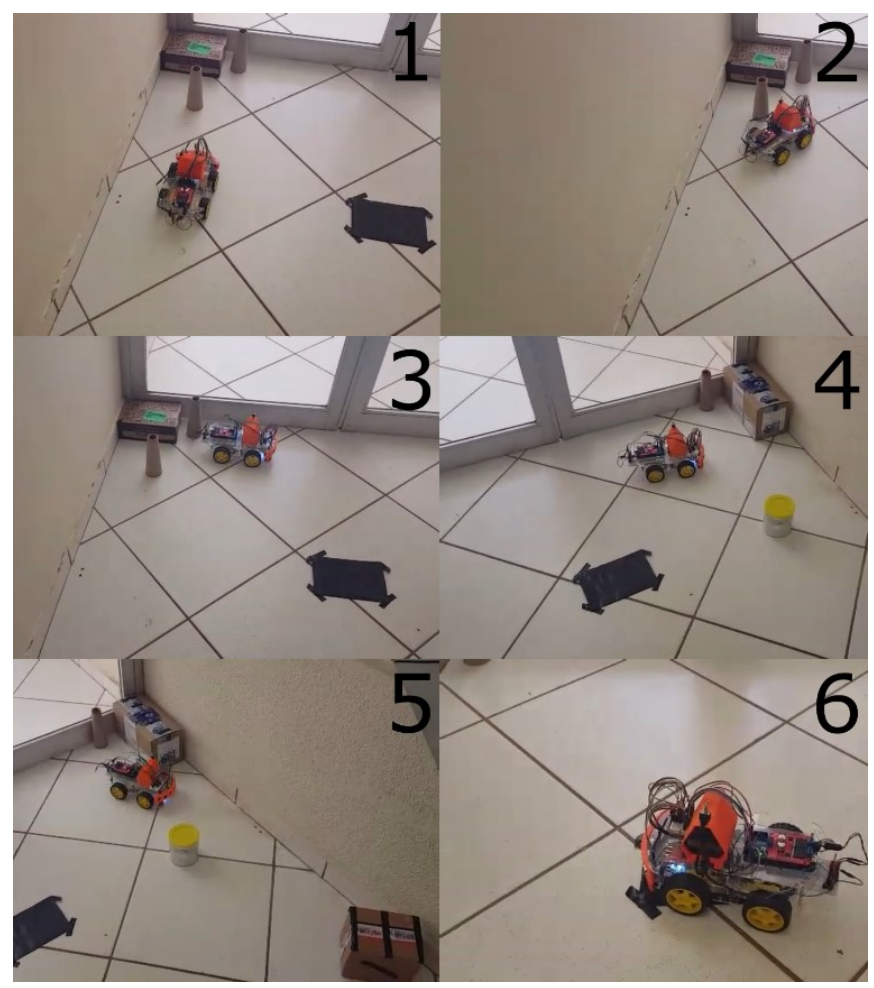

Fig. 9 Initial FCM results.

The objective can be seen in Fig. 9 as the black tape on the ground. When the color sensor detects it, the robot stops, signaling that the destination was found. The robot reached it every time during the tests, with most obstacles being avoided through random dispositions. The first obstacles placed were boxes and empty cans, in a closed environment. After reaching the objective, the robot can be programmed to perform any desired action according to the color found on the ground. This can be useful for multiple objective assessment.

We can observe in Fig. 9 that in 1 and 2 the robot detects the small objects and make a small adjustment in its route to avoid the obstacle. When it gets near the wall, in 3, we can observe a sharper detour since there is a wall nearby and the robot must change its course more aggressively. As the robot keeps going, we can observe another detour as it goes between two objects and a wall, in 4 and 5. Finally, in 6, the robot reaches its destination and stops. The full initial results video can be seen at: https://youtu.be/OLqRSa8Ka7k.

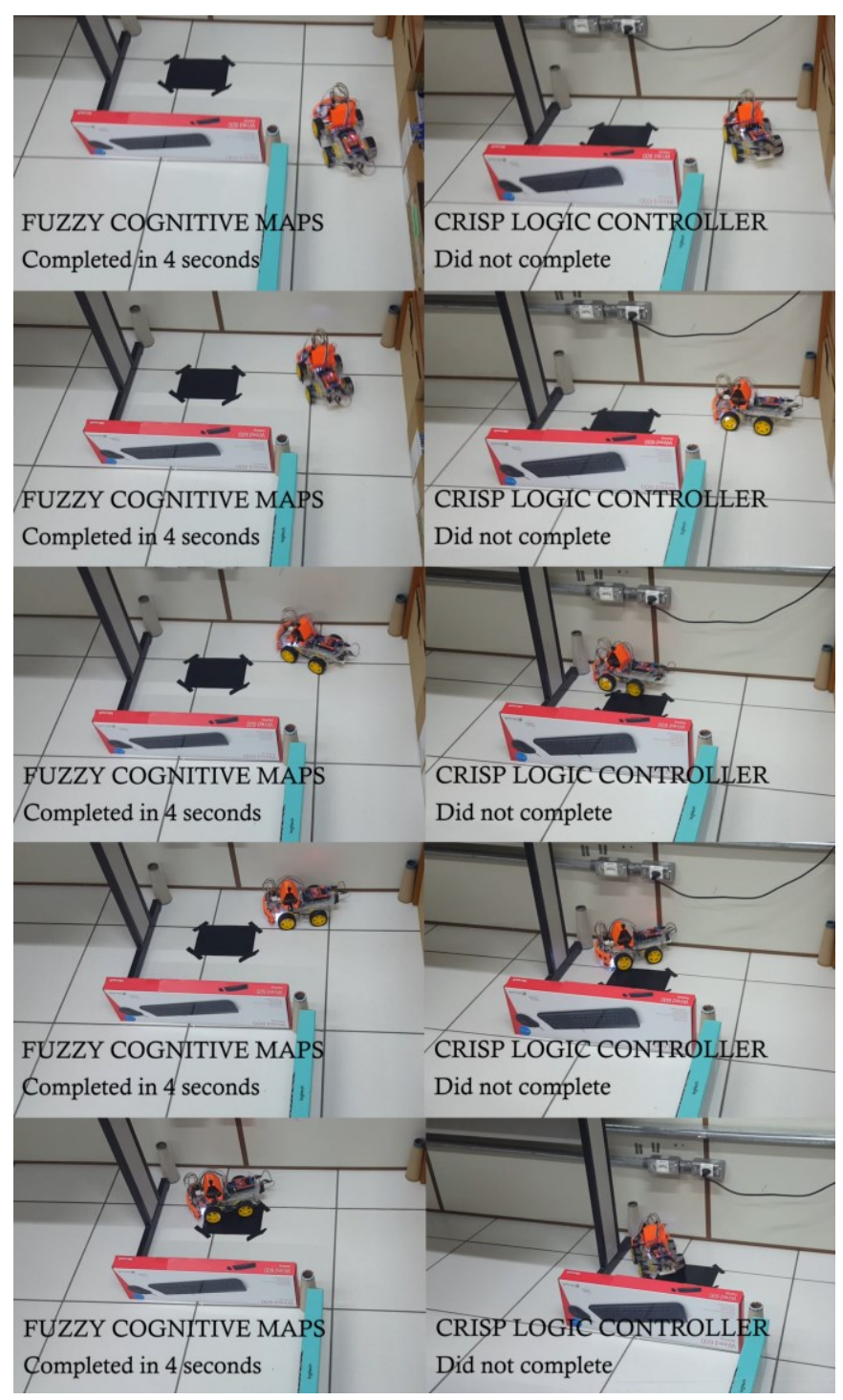

Fig. 10 Side by side controller comparison

During some tests, the prototype took a longer time to find the objective, as the disposition of the obstacles made the robot loop through the same areas a few times. In addition, the robot was able to avoid the dynamic obstacles with ease. These sometimes helped the robot to find the objective, forcing a change in the route.

The second and third tests where more specific, using a smaller route to verify the robot's behavior in small spaces and corridors. This way we could compare both logics side by side, since we forced a predetermined route to the objective. Thus, we can observe subtle and sharper differences between both controllers. The comparison tests video can be watched at: https://youtu.be/vOmcIZFWHBo.

A side by side comparison from the second run can be observed in Fig. 10, where the FCM controller is on the left 
and the Multivalued controller is on the right. Unfortunately, the crisp logic controller did not finish both runs, but the FCM controller found the objective quickly and without any setbacks. The third run can be seen in Fig. 13, it was more elaborated and reflected in a longer time to reach the objective. Again, the crisp controller did not perform positively, this time it returned to the beginning and left the test area. These results showed an optimized trajectory and movement speed from the FCM, with improved detour accuracy, when comparing both controllers. Also, we observed that less power is being delivered to the motors, reflecting in battery economy. Which leads to preserving the motor's physical integrity, as we are not pushing the motors to full-speed with every pulse.

A major setback experienced during the development of the project is that sometimes the robot did not detect small obstacles, which might be related to refraction experienced by ultrasonic sensors. Since the same hardware was tested with a different code script, using multivalued logic showed similar problems. This was a deciding factor for using two different types of distance sensors, as we wanted to reduce sensor imprecision and errors. Given the complexity of the sensors, we also concluded that this robot could also have deliberative behaviors, instead of being purely reactive.

\section{CONCLUSIONS}

According to the results, it can be concluded that FCM can be an effective decision-making tool for low-cost autonomous mobile robots This technique is easy to implement and can be embedded into smaller projects as well as bigger ones.

Obstacle avoidance results are promising, using low cost sensors can be viable, and the simpler code can perform similarly or even better than longer and more complex equivalents. Such example is the multivalued logic that it has been compared to, as the first code can become confusing and have redundant parts. The FCM needs only two functions for the entire decision-making process. In short, the initial real results suggest the validations of kinematic model and prototype, implying that the proposed controller can be used for autonomous robots.

For further projects, we aim to give the robot a notion to where the objective is, in order to prevent endless roaming in big open areas. Another big step is to improve the complexity of the scenarios, such as dynamic environments, to investigate the computational complexity of the proposed controller. Finally, to check the technique of behavior in larger distances to possible industrial applications like industry 4.0.

\section{ACKNOWLEDGEMENTS}

The authors gratefully acknowledge the financial support for this research from CAPES/BRASIL (Process 88887.354058/2019-00), Federal University of Technology Paraná, Cornélio Procópio (UTFPR), the Araucaria Foundation, the Secretary of State for Science, Technology and Higher Education (SETI-PR) and the Government of the State of Paraná for the financial support.

\section{REFERENCES}

Arruda, L. V. R. et al. (2018) 'Artificial Life Environment Modeled by Dynamic Fuzzy Cognitive Maps', IEEE
Transactions on Cognitive and Developmental Systems, 10(1), pp. 88-101.

Bekey, G. A. (2005) Autonomous robots: from biological inspiration to implementation and control, Communication.

de Souza, L. et al. (2017) 'Dynamic Fuzzy Cognitive Maps Embedded and Intelligent Controllers Applied in Industrial Mixer Process', International Journal o $\mathrm{n}$ Advance s in Systems and Measurements, 3(June)

Brooks, R. A. (1986) 'A Robust Layered Control System For A Mobile Robot', IEEE Journal on Robotics and Automation.

Correl, N. (2016) Introduction to Autonomous Robots. Magellan Scientific.

Grassi Jr, V. (2006) ‘Arquitetura Híbrida para Robôs Móveis Baseada em Funções de Navegação com Interação Humana', p. 120.

Kosko, B. (1986) 'Fuzzy cognitive maps', International Journal of Man-Machine Studies, 24(1), pp. 65-75.

Mendonça, M. et al. (2013) 'Autonomous Navigation Applying Dynamic-Fuzzy Cognitive Maps and Fuzzy Logic', in Papadopoulos, H. et al. (eds) Artificial Intelligence Applications and Innovations. Berlin, Heidelberg: Springer Berlin Heidelberg, pp. 215-224.

Mendonça, M. et al. (2016) 'Hybrid Dynamic Fuzzy Cognitive Maps and Hierarchical Fuzzy Logic controllers for Autonomous Mobile Navigation', in 2016 IEEE International Conference on Fuzzy Systems, FUZZ-IEEE 2016.

Mendonça, M. et al. (2017) 'A cooperative architecture for swarm robotic based on dynamic fuzzy cognitive maps', Engineering Applications of Artificial Intelligence. Elsevier, 59(November 2016), pp. 122-132.

NASA (2018) Mars InSight Landing Press Kit. Available at: https://www.jpl.nasa.gov/news/press_kits/insight/landing /download/mars_insight_landing_presskit.pdf.

Papageorgiou, E. I. (ed.) (2014) Fuzzy Cognitive Maps for Applied Sciences and Engineering. Heidelberg: SpringerVerlag Berlin Heidelberg.

Robla-Gomez, S. et al. (2017) 'Working Together: A Review on Safe Human-Robot Collaboration in Industrial Environments', IEEE Access.

Ruspini, E. H. (2002) 'Fuzzy logic-based planning and reactive control of autonomous mobile robots', pp. 10711076.

Siciliano, B. and Khatib, O. (2007) Springer Handbook of Robotics. Berlin, Heidelberg: Springer-Verlag.

Siegwart, R. and Nourbakhsh, I. R. (2004) Introduction to Autonomous Mobile Robots, Robotica.

Steels, L. (1995) 'When are robots intelligent autonomous agents?', Robotics and Autonomous Systems, 15(1-2), pp. 3-9.

Tunstel, E. and Jamshidi, M. (2002) 'Fuzzy logic and behavior control strategy for autonomous mobile robot mapping', pp. 514-517.

Yanguas-Rojas, D. and Mojica-Nava, E. (2017) 'Exploration with Heterogeneous Robots Networks for Search and Rescue', IFAC-PapersOnLine. Elsevier, 50(1), pp. 7935 7940. 